Maria Inês da Rosa ${ }^{1}$

Fabio Rosa Silva ${ }^{1}$

Bruno Rosa Silva ${ }^{1}$

Luciana Carvalho Costa ${ }^{1}$

Angela Mendes Bergamo ${ }^{1}$

Napoleão Chiaramonte Silva ${ }^{1}$

Lidia Rosi de Freitas Medeiros ${ }^{1}$

Iara Denise Endruweit Battisti ${ }^{2}$

Rafael Azevedo ${ }^{1}$

\title{
A randomized clinical trial on the effects of remote intercessory prayer in the adverse outcomes of pregnancies
}

\author{
Ensaio clínico randomizado sobre os efeitos \\ da oração intercessória nos desfechos adversos da gestação
}

Laboratório de

Epidemiologia,

Universidade do Extremo

Sul Catarinense. Av.

Universitária 1105 ,

Pinheirinho. 88.806-000

Criciuma SC.

mir@unesc.net

${ }^{2}$ Universidade Fronteira Sul.

\begin{abstract}
The scope of this article was to investigate whether intercessory prayer (IP) influences the adverse outcomes of pregnancies. A doubleblind, randomized clinical trial was conducted with 564 pregnant women attending a prenatal public health care service. The women were randomly assigned to an IP group or to a control group ( $n=289$ per group). They were simultaneously and randomly assigned to practice prayer off-site or not. The following parameters were evaluated: Apgar scores, type of delivery and birth weight. The mean age of the women was 25.1 years of age $( \pm 7.4)$, and the average gestational age was 23.4 weeks ( \pm 8.1$)$. The average number of years of schooling for the women was 8.1 years $( \pm 3.1)$. The women in the IP and control groups presented a similar number of adverse medical events with non-significant p. No significant differences were detected in the frequency of adverse outcomes in pregnant women who practiced IP and those in the control group.
\end{abstract}

Key words Intercessory prayer, Randomized clinical trial, Pregnant women, Excess birth weight, Apgar scores, Birth weight
Resumo Este artigo tem por objetivo investigar se a oração intercessória influencia os desfechos adversos das mulheres grávidas. Foi realizado ensaio clínico randomizado duplo-cego com uma população de 564 gestantes que frequentavam Serviço de pré-natal de serviço público de saúde. As gestantes foram aleatoriamente designadas para grupo de intercessão ou grupo controle ( $n=289$ por grupo). Foram avaliados os seguintes parâmetros: indice de Apgar, tipo de parto, peso ao nascer. A idade média das mulheres foi de 25,1 anos $( \pm 7,4) e$ a idade gestacional média foi de 23,4 semanas ( \pm 8,1). A média de anos de escolaridade foi de 8,1 anos $( \pm 3,1)$. As mulheres que receberam intervenção (Oração intercessória) e grupo controle exibiram um número similar de eventos adversos, com p não significativo. Não encontramos diferença significativa entre os desfechos adversos na gestação entre os grupos que receberam oração intercessória e no grupo controle.

Palavras-chave Oração intercessória, Ensaio clínico randomizado, Gestantes, Macrossomia, Apgar, Baixo peso 


\section{Introduction}

Praying for help and healing is a fundamental practice in most societies; however, the object to which these prayers are directed varies among the religions in the world ${ }^{1}$. Ninety five percent of Americans claim to believe in God, and 58\% report that religion forms is a very important part of their lives ${ }^{2}$. Many Americans also use religious activity to cope with stressful life events, such as, a diagnosis of cancer ${ }^{3}$. Although religion is important to many patients, physicians tend to ignore the religious beliefs of their patients when taking care of them ${ }^{4}$.

In 2001, the US National Center for Complementary and Alternative Medicine defined "frontier medicine" as a group of therapies "for which there is no plausible biomedical explanation" ${ }^{\prime \prime}$. There are many different forms of prayer, such as, organized prayer to God according to an advanced belief system, individual sporadic prayer, spiritual healing, meditation and thanksgiving. Prayers can be spoken from within the framework of a variety of faiths and also by individuals who do not ascribe to a particular, formalized belief system.

Many studies claim to have demonstrated the effectiveness of intercessory prayer(IP) in improving disease ${ }^{6,7}$. Byrd ${ }^{6}$ measured the efficacy of IP in curing diseases. They found that $14 \%$ of the subjects who practiced IP and $22 \%$ of the subjects in the control group had a poor outcome during hospitalization, and this difference was statistically significant.

However, many of these claims are not adequately supported. One meta-analysis of 14 controlled studies concluded that there is no scientifically discernible treatment effect for IP ${ }^{8}$. Additional reports in the literature are inconclusive, and the general consensus in the field is that the current evidence is compelling enough to warrant further investigation. Although the results of individual studies suggest a positive treatment effect of IP, most of the studies do not support this claim because the evidence does not support a recommendation either in favor or against practicing IP'. Therefore, the aim of this study was to investigate whether IP had an effect on the adverse outcomes of a group of pregnant women.

\section{Methods}

\section{Trial design}

We conducted a double blind, randomized controlled trial with 564 pregnant women attending a prenatal care public health service clinic between February 2008 and December 2008. The study was approved by the University of Extremo Sul Catarinense Ethics Committee. All participants signed an informed consent.

\section{Participants}

Pregnant women (578) were enrolled into the study. The exclusion factor was being pregnant for over 37 weeks because of the proximity of the delivery could not do the intervention on time.

\section{Intervention}

A group of six women, who were selected to pray for nine consecutive days, the same pray for all pregnant women from the intervention group. The group of women who practiced IP was coordinated by a theologian, who led a prayer asking for a good delivery and a healthy newborn.

\section{Outcomes}

The outcomes analyzed were as follows: type of delivery, Apgar scores, birth weight and macrossomy. The independent variables analyzed were: age, length of gestation, associated diseases, belief in God and religion. All variables were dichotomized.

\section{Sample size}

Based on Byrd's study ${ }^{6}$ we evaluated the table that represents the calculation for the different proportions using the chi-square test to compare the proportions of dichotomous variables ${ }^{10}$. Based on this evaluation, we found that, considering a bidirectional alpha $=0.05$ and beta $=0.20$, the difference between the proportions was $10 \%$, for a total number of 289 women per group. In this study 578 pregnant women were enrolled at baseline.

\section{Randomization}

All the interviews for the enrollment of the subjects into the study were performed by one of two staff members, who assigned enrollment 
numbers to the subjects. After enrollment was complete, a staff member used a random number table to assign study codes to each of the subjects' enrollment numbers. These codes were then randomized by a computer. Only this researcher had knowledge of who was in the treated group, and control group and this research was who contacted the coordinator of the group of intercessors providing the first name of the pregnant woman. The patients were then simultaneously and randomly assigned to practice or not to practice prayer off-site. Half of the patients were randomly assigned to the IP group, and the other half was assigned to the control group ( $\mathrm{n}=289$ per group).

\section{Blinding}

This study was double blind. None pregnant woman knew if would receive intercessory prayer or not. There searcher also had no knowledge of who was the group that received the intervention and who did not. The IP group coordinator was blinded to the identity of the subjects, with only the subjects' first name being provided.

\section{Statistical analysis}

The baseline continuous variables were compared using the Student t-test. The baseline and outcome categorical variables were compared using the chi-square test. Risk ratios and 95\%
CIs were used for the comparison of the groups. A Poisson robust regression model was used to evaluate whether baseline covariates, were associated with the occurrence of complications in the delivery and to assess the consistency of the unadjusted and final models. Pre-specified covariates were included in model, and variables with P-values of less than 0.05 were retained in the final models. Statistical analyses were performed using STATA version 9 software.

\section{Results}

Eight pregnant women from the IP group and five from the control group were lost during follow-up. Therefore, our final analysis included 281 pregnant women from the IP group and 285 pregnant women from the control group (Figure1).

The mean age of the women was 25.1 years old $( \pm 7.4)$, and the average gestational age was 23.4 weeks $( \pm 8.1)$. The average years of schooling for the women was 8.1 years $( \pm 3.1)$. As shown in Table 1, the two groups of women had similar baseline characteristics. The only difference between the groups was the number of abortions that they had previously undergone $(\mathrm{P}=0.007)$.

Both groups of women had a similar number of serious medical adverse events, including spontaneous abortion $(\mathrm{p}=0.53)$, intrauterine death and stillbirth $(\mathrm{p}=0.30)$, low Apgar score $(\mathrm{p}=0.34)$, preterm birth $(\mathrm{p}=0.33)$, small size

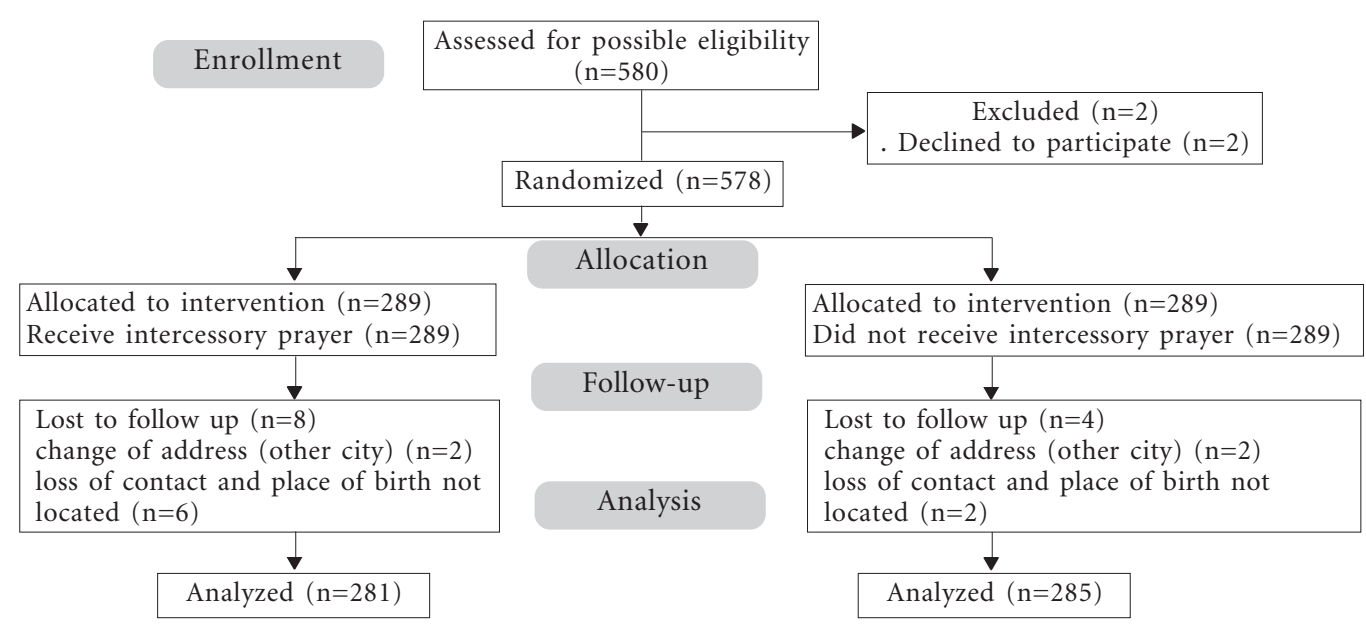

Figure 1. Enrollment of study patients. 
for gestational age $(\mathrm{p}=0.62)$, macrossomy $(\mathrm{p}=$ $0.09)$, cesarean delivery $(\mathrm{p}=0.68)$ and malformation $(\mathrm{p}=0.99)$ (Table 2).

Table 1. Baseline characteristics of the subjects.

\begin{tabular}{lrr}
\hline \multicolumn{1}{c}{ Characteristic } & $\begin{array}{c}\text { Prayer group } \\
(\mathbf{n}=\mathbf{2 8 1})\end{array}$ & $\begin{array}{c}\text { Control Group } \\
(\mathbf{n}=\mathbf{2 8 5})\end{array}$ \\
\hline Age & & \\
$2-34$ years & $160(57.1 \%)$ & $167(58.8 \%)$ \\
$\leq 19$ years $\geq 35$ years & $120(42.9 \%)$ & $117(41.2 \%)$ \\
Age (mean \pm s.d.) & $24.63 \pm 7.27$ & $25.58 \pm 7.53$ \\
Gestational age & & \\
$\geq 33$ weeks & $45(16.1 \%)$ & $59(20.9 \%)$ \\
25 - 32 weeks & $60(21.5 \%)$ & $71(25.2 \%)$ \\
$13-24$ weeks & $141(50.5 \%)$ & $123(43.6 \%)$ \\
$\leq 12$ weeks & $33(11.8 \%)$ & $29(10.3 \%)$ \\
Gestational age (mean \pm s.d.) & $22.59 \pm 8.06$ & $24.13 \pm 8.09$ \\
Education & & \\
Elementary school educ. & $164(58.4 \%)$ & $173(60.9 \%)$ \\
Incomplete secondary educ. $117(41.6 \%)$ & $111(39.1 \%)$ \\
Marital status & & \\
Married/partner & $236(84.0 \%)$ & $244(85.9 \%)$ \\
Single/Separated & $45(16.0 \%)$ & $40(14.1 \%)$ \\
Previous pregnancy (yes) & $149(53.0 \%)$ & $159(55.8 \%)$ \\
Previous abortions (yes) & $29(10.3 \%)$ & $52(18.3 \%)$ \\
Religion & & \\
None & $26(9.3 \%)$ & $22(7.8 \%)$ \\
Catholic & $168(59.8 \%)$ & $168(50.2 \%)$ \\
Gospel & $81(28.9 \%)$ & $90(31.7 \%)$ \\
Other & $6(2.1 \%)$ & $4(1.4 \%)$ \\
\hline
\end{tabular}

* Using chi-square test.

\section{Discussion}

Distant IP appears to have no significant effect on the outcome of pregnant women. This rigorously designed blind, randomized controlled trial conducted with pregnant women showed no significant effect in adverse outcomes of distant IP. However, there are numerous challenges when designing and conducting a study of IP. First, because there is no accepted scientific basis for the effects of IP on illness, it is very difficult to select a biologically relevant patient outcome to study in a clinical trial. Also, the selected outcome may not be associated with the effects of IP, making it difficult to interpret the results of such a study. Second, the duration of IP that should be practiced to observe an effect is not known, which is due, in part, to the lack of a biological basis for the effects of IP. Investigations of the potential therapeutic effects of IP have been conducted on a variety of health areas including: cardiology ${ }^{6,11,12}$, diabetes ${ }^{13}$, alcoholism ${ }^{14}$, mental health ${ }^{15}$, arthritis ${ }^{16}$, infections ${ }^{17}$ and fertility ${ }^{18}$. Additionally, because the type of IP practiced in a study may be inadequate to evaluate the outcome of the studies, the lack of an effect could be due to inadequate treatment. Similarly, while it may be appealing to suggest that there is a dose-dependent relationship between IP and outcome, the lack of a known mechanism for the effects of IP prevent us from conducting such an analysis. Third, because it is impossible (and not desirable) to limit the prayer practiced by family, friends and others, a study of IP can only evaluate the effects of additional IP, not the effects of prayer in general. Also, the intervention (interces-

Table 2. Outcome of the patients.

\begin{tabular}{lccc}
\hline \multicolumn{1}{c}{ Characteristics } & $\begin{array}{c}\text { Prayer group } \\
(\mathbf{n = 2 8 1})\end{array}$ & $\begin{array}{c}\text { Control Group } \\
(\mathbf{n}=\mathbf{2 8 5})\end{array}$ & p-value $^{*}$ \\
\hline Apgar score at 5 min & & & \\
$\quad 0-3$ & $1(0.6 \%)$ & $1(0.5 \%)$ & \\
$4-7$ & $2(1.1 \%)$ & - & \\
$8-10$ & $178(98.3 \%)$ & $191(99.5 \%)$ & 0.344 \\
Preterm (yes) & $8(3.9 \%)$ & $13(6.0 \%)$ & 0.330 \\
Birth weight & $12(6.5 \%)$ & $15(7.8 \%)$ & 0.628 \\
$\quad$ Small for gestational age $\left(10^{\text {th }}\right.$ percentile $)$ & $5(2.7 \%)$ & $12(6.3 \%)$ & 0.099 \\
$\quad$ Macrossomy $(>4000 \mathrm{~g})$ & $3248,65 \pm 517,19$ & $3218,59 \pm 516,88$ & 0,575 \\
Birth weight (mean \pm s.d.) & $108(52.9 \%)$ & $109(50.9 \%)$ & \\
Type of delivery & $96(47.1 \%)$ & $105(49.1 \%)$ & 0.681 \\
$\quad$ Vaginal & &
\end{tabular}

*Using chi-square test. 
sory prayer) only includes the IP provided by the intercessors, not the effect or result of communication with God. Fourth, documentation of how and when IP is practiced and the inclusion of a specific intention may interfere with the usual practice of the intercessors. The IP practiced during a clinical trial may be different from the IP usually conducted by the intercessors, limiting the interpretation of the results. Given these challenges, it is not surprising that previous studies of IP are controversial $^{18,19}$.

Only a few clinical trials have found an association between remote prayer and adverse outcomes (generally defined as intermediate clinical endpoints, self-reported health status, morbidity or mortality). In a trial of 393 coronary care unit (CCU) patients, Byrd ${ }^{6}$ found a statistically significant positive effect between Christian prayer "to a Judeo-Christian God" and six out of 26 outcome variables, as well as with a global hospital course score. Harris et al. ${ }^{11}$ replicated Byrd's findings, finding no effect on 31 additional clinical variables. However, Harris et al. ${ }^{11}$ developed a CCU course score specific to their study, which improved significantly (by 10\%) in the subjects who prayed.

A recent systematic review of the literature described multiple randomized trials in which other interventions versus personal, focused, committed and organized IP (guided by intercessors holding some belief that they are praying to God or a god) were compared. The review described prayer that was offered on behalf of anyone with health problems and included ten studies (7646 total patients). A comparison of IP plus standard care versus standard care alone revealed that there was no clear effect of IP on death; the effect of IP on death was not statistically significant, and the data were heterogeneous [6 randomized controlled trials (RCTs), $\mathrm{n}=6784$, random-effects, RR: 0.77, CI: 0.51 to 1.16 , I2: $83 \%$ ]. Additionally, there was no significant difference between the groups with respect to their general clinical state (5 RCTs, $\mathrm{n}=2705$, RR intermediate or bad outcome: 0.98 , CI: 0.86 to 1.11). Four studies found no effect of IP on re-admission to the CCU (4 RCTs, $\mathrm{n}=2644$, RR: 1.00, CI: 0.77 to $1.30)$, and two other trials found that IP had no effect on re-hospitalization rate ( 2 RCTs, $\mathrm{n}=1155$, RR: 0.93, CI: 0.71 to 1.22). Overall, the review con- cluded that, although the findings are equivocal and some of the results suggest a positive treatment effect of IP, most studies do not reach this conclusion, and the evidence does not support a recommendation either for or against the use of IP. We are not convinced that further trials of IP should be undertaken and rather suggest that any resources available for such a trial should be used to investigate other questions in healthcare ${ }^{9}$. Jørgensen et al. ${ }^{20}$ made a critical analysis of the above mentioned systematic review saying that, "this Cochrane Reviews article, which evaluates a mixture of theological and scientific arguments, is unsound and unhelpful and would, if accepted, make all scientific endeavors meaningless. The review fails badly to live up to the high standards required for Cochrane Reviews, and we therefore suggest it be withdrawn". Our negative findings do not imply that therapeutic relationships and positive therapeutic intent do not have beneficial treatment effects for individual patients. Rather, we suggest that additionally studies using different methodological approaches are required.

The evidence-based medicine (EBM) movement was established to combat capricious reasoning in clinical care, particularly arguments from authorities in the field. The critique of authority and appraisal of evidence remain EBM's core values and should be revisited in this era of EBM's maturity and influence. We are now faced with a new form of under-questioned authority and evidence from well-designed and methodologically appraised RCTs. The evidence from RCTs is now prized, even when it is incapable of providing meaningful information, particularly when the underlying causal theory is inscrutable. The evidence obtained from experimental trials in support of remote IP provides us with an illustrative view that highlights systematic scientific blind spots in the institutions of EBM. At its core, medicine, including evidence-based medicine, is based on theory. Thus, EBM must cultivate greater capacity to address the crucial role of theory in both the generation and use of experimental evidence ${ }^{21}$.

This study was designed, conducted and reported in accordance with the Consolidated Standards of Reporting Trials (CONSORT) ${ }^{22}$. The most recent guidelines for conducting RCTs were also taken into account ${ }^{23}$. 


\section{Collaborators}

FR Silva, MI Rosa, designed the study, drafted the manuscript and analyzed the data. BR Silva, AM Bergamo, LC Costa, R Azevedo and IDE Battisti conceptualized the study, interpreted the data and critically evaluated the manuscript. LR Medeiros, NC Silva and MI Rosa revised and critically evaluated the manuscript.

\section{References}

1. Spivak CD. Hebrew prayers for the sick. Ann Med Hist 1917; 1:83-85.

2. Gallup G. Religion in America 2000. Princeton: Princeton Religious Research Center; 2000

3. Eisenberg DM, Davis RB, Ettner SL, Appel S, Wilkey S, Van Rompay M, Kessler RC. Trends in alternative medicine use in the United States, 1990-1997: results of a follow-up national survey. JAMA 1998; 280(18):1569-1575

4. Maugan TA, Wadland WC. Religion and family medicine: a survey of physicians and patients. Fam Pract 1991; 32(2):210-213.

5. Straus S, Nahin R. Minutes of the Sixth Meeting Bethesda: National Center for Complementary and Alternative Medicine; (Feb 5)2001. [serial on the Internet]. [cited 2013 Jun 21]. Available from: http:/ /nccam.nih.gov/about/naccam/minutes/2001 feb.htm?nav=gsa

6. Byrd RC. Positive therapeutic effects of intercessory prayer in a coronary care unit population. South Med J 1988; 81(7):826-829.

7. Krucoff MW, Crater SW, Green CL, Maas AC, Seskevich JE, Lane JD, Loeffler KA, Morris K, Bashore $\mathrm{TM}$, Koenig HG. Integrative noetic therapies as adjuncts to percutaneous intervention during unstable coronary syndromes: Monitoring and Actualization of Noetic Training (MANTRA) feasibility pilot. Am Heart J 2001; 142(5):760-769.

8. Masters KS, Spielmans GI, Goodson ST. Are there demonstrable effects of distant intercessory prayer? A meta-analytic review. Ann Behav Med 2006; 32(1):21-26

9. Roberts L, Ahmed I, Hall S. Intercessory prayer for the alleviation of ill health. Cochrane Database System Rev 2000; (2):CD0003688.

10. Browner WS, Newman TB, Cummings SR, Newman TB. Estimating sample size and power: the nitty-gritty. In: Hulley SB, Cummings SR, Browner WS, Grady D, Hearst N, Newman TB. Designing Clinical Research. $3^{\text {th }}$ Edition. Philadelphia: Linppincott, Williams \& Wilkins; 2001. p. 65-93.

11. Harris WAS, Gowda M, Kolb JW. Strychacz CP, Vacek JL, Jones PG, Forker A, O’Keefe JH, McCallister $\mathrm{BD}$. A randomized, controlled trial of the ef fects of remote, intercessory prayer on outcomes in patients admitted to the coronary care unit. Arch Intern Med 2000; 159(19):2273-2278.

\section{Acknowledgments}

This work was supported by the Foundation for the Support of Scientific and Technological Research of Santa Catarina (FAPESC).
12. Aviles JM, Whelan SE, Hernke DA, Williams BA, Kenny KE, O’Fallon WM, Kopecky SL. Intercessory prayer and cardiovascular disease progression in a coronary care unit population: A randomized controlled trial. Mayo Clin Proc 2001; 76(12):1192-1198.

13. Wirth D, Mitchekk B. Complementary healing therapy for patients with Type 1 Diabetes Mellitus. J Sci Explor 1994; 8(3):350-361.

14. O'Laoire S. An experimental study of the effects of distant, intercessory prayer on self-esteem anxiety, and depression. Altern Ther Health Med 1973; 3(6):38-53.

15. Matthews DA, Marlowe SM, MacNutt FS. Effects of intercessory prayer on patients with rheumatoid arthritis. South Med J 2000; 93(12):1177-1786.

16. Leibovici L. Effects of remote, retroactive intercessory prayer on outcomes in patients with bloodstream infection: A randomized controlled trial. $\mathrm{Br}$ Med J 2001; 323(7327):1450-1451.

17. Cha KY, Wirth DP, Lobo RA. Does prayer influence the success of in vitro fertilization-embryo transfer? Report of a masked, randomized trial. J Reprod Med 2001; 46(9):781-787.

18. Dusek JA, Sherwood JB, Friedman R, Myers P, Bethea CF, Levitsky S, Hill PC, Jain MK, Kopecky SL, Mueller PS, Lam P, Benson H, Hibberd PL. Study of the Therapeutic Effects of Intercessory Prayer (STEP): study design and research methods. Am Heart J 2002; 143(4):577-584.

19. Oldnall AS. On the absence of spirituality in nursing theories and models. J Adv Nurs 1995; 21(3):417-418.

20. Jørgensen KJ, Hróbjartsson A, Gøtzsche PC. Divine Intervention? A Cochrane review on intercessory prayer gone beyond science and reason. J Negat Results Biomed 2009; 8:7.

21. Giacomini M. Theory-Based Medicine and the Role of Evidence Why the Emperor Needs New Clothes, Again. Perspect Biol Med 2009; 52(2):234-251.

22. Moher D, Schulz KF, Altman D. The CONSORT statement: revised recommendations for improving the quality of reports of parallel-group randomized trials. JAMA 2001; 285(15):1987-1991.

23. Schulz KF, Altman DG, Moher D, CONSORT Group. CONSORT 2010 Statement: Updated guidelines for reporting parallel group randomised trials. J Clin Epidemiol 2010; 63(8):834-840

Artigo apresentado em 20/06/2012

Aprovado em 17/09/2012

Versão final apresentada em 02/10/2012 